\title{
Concept of Inclusive Optimal Performance (IOP): Theoretical and Conceptual understanding on the inclusive relationship between Internal Simultaneous Performance (ISP) and External Simultaneous Performance (ESP)
}

\author{
Received: 25-Jul-2019 | Accepted: 9-Jul-2020
}

\author{
Rizwan Ellahi $^{*}$ iD $\mid$ Noman Mahmood $^{2}$ iD $\mid$ Bazla Ali Khan $^{3}$ iD
}

\begin{abstract}
Small and Medium Enterprises play a significant role in economic well-being of a society, but unfortunately there is lack of proper structure and system for application of performance measurement in most of the SMEs. Hence, an inconsistency amongst the performance measures can be observed. The following paper focuses upon distinctive nature of small and medium business organizations (SMEs) and proposes a framework for effective performance measurement with respect to (SMEs). This research aims to provide such a framework for performance measurement that can ensure a balance between internal and external performance measures by introducing the concept of inclusive optimal performance (IOP) as a resultant of inclusive working between internal simultaneous performance (ISP) and external simultaneous performance (ESP). The need for inclusive strategic approach to internal and external performance factors has arrived primarily because of one sided competitiveness is produced due to exclusive strategic approach to inclusive and external performance factors of organization. In order to explore the legitimacy of the depicted argument the following research is based on concept review methodology of literature review through which this research assess the extensive literature with respect to performance measurement systems within SMEs. Through the integration of the psychology-oriented constructs of the internal and external locus of control theory, this research stem the inclusive nature and working of internal and external factors of performance analogy as a basis of the proposed framework that can be applied to ensure effective performance measurement at SMEs.
\end{abstract}

Keywords: Performance Measurement, Management Systems, SMEs, Performance Measurement Framework

JEL Classification: $P 17, P 27, P 47, D 21, D 22$

\section{Author's Affiliation:}

Institution:

Institute of Business Management $t^{1,2,3}$

Country: Pakistan

Corresponding Author's Email: *rizwanmatloob786@gmail.com

The material presented by the author(s) does not necessarily portray the view point of the editors and the management of the ILMA University, Pakistan.

2409-6520 (Online) 2414-8393 (Print) (C2020, published by the ILMA University, Pakistan.

This is open access article under the @- $\odot$ license. https://creativecommons.org/licenses/by/4.0/

Page | 101 


\section{1) INTRODUCTION}

There are a wide variety of definitions as well as criteria to classify SMEs, we have considered the definition of SMEs being followed in Pakistan. According to Qureshi et al., (2009), the Small Medium Enterprises (SMEs) in Pakistan are defined on the basis of the number of the employees. If an organization has around 250 people together with a paid-up capital of approximately Rs. 25 million and the annual sales generated by the company is estimated to be around Rs. 250 million, then it would be labelled as an SME (Kureshi, Mann, Khan, \& Qureshi, 2009). This definition was developed after carrying out an exhaustive consultation process over a time period of two years. During this time, the definition was reviewed several times at different levels within the government before final endorsement by the Federal Cabinet in 2007 (SMEDA, 2017).

Small and medium enterprises are major employment providers all over the world. However, they exhibit significantly lower performance levels when compared with large enterprises. SME low performance often co-exists with poor management practices as well as low market share, unskilled labor and poor operational environment. Current empirical investigation and theoretical elaborations highlight the need for greater development of management systems in SMEs. As highlighted by Hansen et al.(2002) points out that the competitive position of an organization tends to improve when the technical innovations are accompanied by adequate organizational changes and certain innovation thresholds, also known as "thresholds for chaos". As a result, the organizational and managerial developments become essential for the survival of SMEs (Hansen, Sonderga ${ }^{\circ} \mathrm{rd}$, \& Meredith, 2002).

Over last 20 years the measurement of business performance has been deliberated by adopting different perspectives of analysis that can be grouped into two lines of study, the first focused on control systems management (Management Control System - MCS), the second on the systems of performance measurement (Performance Measurement System - PMS). Studies on management control systems are characterized by a contingent approach according to which each organization should adopt a performance measurement system defined on the basis of some situational variables such as strategy, organizational culture, technology, etc. (Simons, 1994; Ferreira \& Otley, 2009).

Previous literature on management control offers numerous empirical researches that maintain a predominant focus on the aspects that are eco-financial and out of that dimension develop a pre-validly research, both theoretical and empirical, using architects proposed by the studies on performance measurement systems. Their Business dimension is cited as a contingent factor, but there are no specific studies on small and medium enterprises (Chenhall, 2003).

Gulbro et al. (Are small manufacturers failing the quality test?, 2000) have indicated that large companies put more stress on continuous improvements and PMS as compared to the SMEs. In order to continuously improve them, larger companies gather data regularly as well as use benchmarking techniques to measure the customer satisfaction (Gulbro, 2000). Another study indicated that smaller 
firms tend to rate their products to be lower in comparison to the larger firms. This is because of the reason that SMEs consider few performance measures mainly financial (Kueng, 2000). Hudson, Bennett, \& Bourne (1999) have also analyzed the pain points related to performance indicators gathered by SMEs based in United Kingdom and discovered that most of the measures adopted by enterprises are financially focused and such performance indicators were ignoring the daily operations of an organization (Hudson, Bennett, Smart, \& Bourne, 1999).

In the last 20 years, following criticism of the "traditional models" of accounting nature, the literature on performance measurement systems has developed a series of models that include the presence of typology of measures of a different nature and the systematic review of the objectives and priorities kept under control (dynamic). These models are mainly generic, i.e. they do not consider the size of the company, and are defined by reference to the characteristics of the large organizations (Neely, Gregory, \& Platts, 2005). The literature on the measurement systems of performance is characterized by a reduced number of empirical researches on the use of the proposed models and a limited attention to SMEs. Only two of the many PMS models are specifically developed with respect to SMEs (Chennell, et al., 2000; Laitinen, 2002).

As per a survey by Neely and Mills (1993) cost of performance measurement is also considered as a burden by managers in SMEs (Neely \& Mills, 1993). According to Elenkov (1997), a properly applied performance measurement system can assist small enterprises in order to assess and respond the risk related with the external environment on a timely basis. He also emphasized that it is important for managers to interpret and respond to these changes on a timely manner. A proper applied performance measurement system can act as a tool to track shifts in environment and assists enterprises in identifying opportunities and to address threats, thus leading towards gaining a competitive advantage.

\section{2) RESEARCH PROBLEM}

Researchers have emphasized upon the usefulness of information derived through internal and external perspectives, however there is lack of literature over inclusive strategic approach and joint working of internal and external performance factors. This lacking leads to exclusive internal and external formulation of strategies and thus enhancing competitiveness of either internal or external performance factors, leaving collecting organizational success at stake (Dutton \& Freedman, 1985; Hambrick, 1982; Jelinek, 1979). Therefore, this research extends upon the concept of optimal performance and introduces it as a joint resultant of inclusive relationship between internal and external performance factors, called inclusive optimal performance (IPO). We define inclusive optimal performance (IOP) as simultaneous integration of vertical optimal performance, called external simultaneous performance (ESP) and horizontal optimal performance, called, internal simultaneous performance (ISP). The integration and inclusively combined working of internal and external performance will provide a mapping approach to organizations to check their positioning in terms of performance, and better strategize towards the gaps of performance. A research by Greenley and Foxall

Page $\mid 103$ 
(1997) indicates that organizations related with multiple stakeholder orientation are highly expected to outperform those with a single stakeholder orientation (e.g. those with a customer orientation). The research further suggests that taking into consideration just a few factors such as marketing philosophy or culture will not ensure success and thus organizations needs to be implicit. Implicit is the marketing orientation that suggests actions and concerns of both internal and external markets (Greenley \& Foxall, 1997).

Looking over the current practices and after proper observation and review of literature, our research has identified that even though the performance measures have been developed, there exists a lack of application in SMEs, More over it has also been witnessed that a lot of stress has been put upon the two dimensions of measures mainly financial and non-financial measures, After thorough analysis of the literature and structure of performance measurement systems we have identified that there can be more distinct and diverse dimensions for performance measurements. Different dimensions such as internal and external measures have been discussed throughout the literature but no proper model or framework has been provided that emphasizes over the adaptation of measures with a perspective to indicate performance in relation to internal and external factors.

According to Kennerly \& Neely, (2000) effectively created PMS can be characterized that incorporates following characteristics:

- The measures used by an organization must provide a 'balanced' picture of the business.

- The framework of measures should provide a succinct overview of an organization's performance.

- The performance measures should be multi-dimensional.

- The performance measurement matrix (PMM) provides comprehensive mapping.

- The performance measures should be integrated across the organization's functions and through its hierarchy.

- The performance measurement system can provide data for monitoring past performance and planning future performance. It implies the measures should gauge both results and as well as the drivers of the results (Kennerley \& Neely, 2000).

It must be noted that even though contemporary businesses measure their performance in terms of internal and external factor, there is an imbalance in application, some enterprises focus more over the internal factors while others are inclined towards focusing on external factors, we believe that such practices are resulting in underutilized resources and incomplete performance measurement, we suggest that a frame work is required that portrays a balance of both external and internal measures.

\section{3) METHODOLOGY/APPROACH}

The approach of this paper is to explore the legitimacy of the argument presented 
above. In order to do so, the paper encompasses review of various measures adapted by enterprises along with their application and strategy. The paper has assessed the extensive literature with respect to performance measurement systems within SMEs. After in-depth analysis, it was observed that there is no formal framework for application of balanced performance measures at SMEs; therefore, this research aims to provide a framework for performance measurement at SMEs. The study can further be used to identify the neglected areas and pain points of performance measurement systems applied by SMEs.

This paper, attempts to follow the concept review approach for literature review approach applied by Morris \& Sexton (1996); Wang, Volkow, Thanos, \& Fowler (2004); Meyer, Becker, \& Vandenberghe (2004); Spillane, Halverson, \& Diamond (2004); Murschetz (2005); Fernández \& Bonillo (2006); Dostilio, et al. (2012); Carter \& Goldstein (2014); Cavaco \& Machado (2014); Shrivastava, Boylan, Bureau, De Sousa, \& Shah (2015); Tamayo, Romero, Gamero, \& Román (2015); Negro (2015); Shek, Yu, \& Busiol (2015); Shi, Li, Hu, \& Wang (2018); Houwer (2020) to explore the conceptual understanding of organizational performance by discussing against unidimensional nature of performance through; (a) providing theoretical understanding of inclusive optimal performance as a superordinate category (b) then instrumentalizing the nature of the optimal performance by providing duality in its operational conception with respect to its internal and external second order dimensions; (b) then reviewing each internal and external second order dimension as locus of control that works simultaneously with having third order constructs in each dimension, such as financial aspects, manufacturing control, human capital, market orientation and stakeholder relationships; (d) then explaining how each third order construct is measured through different indicators that help in operationalizing the entire framework of optimal performance measurement for implementation.

Figure 1 Theoretical Background Structure (Higher Order Abstraction with Concept Reviews)

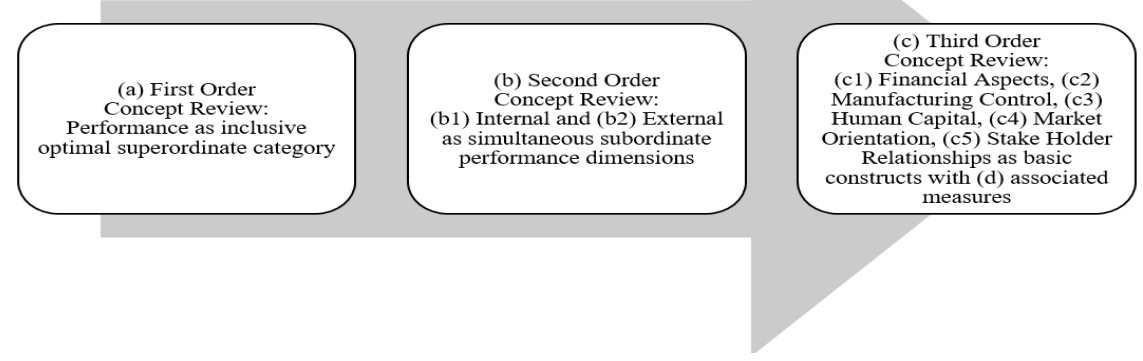

\section{LITERATURE REVIEW}

The paper encompasses review of various measures adapted by enterprises along with their application and strategy. As there is no formal framework for application of balanced internal and external performance Page $\mid 105$ 
IBT JOURNAL OF BUSINESS STUDIES (IBT-JBS) Volume 16 Issue 1, 2020

measures at SMEs, the research aims to provide such a framework for performance measurement at SMEs that ensures optimal performance.

The term performance measurement can be defined within a number of perspectives, howeverthedescription below can be adecentreflection of performancemeasurement.

- A procedure to evaluate the effectiveneess and efficiency of an action or task.

- A performance measure is metric that can be applied towards measureing the effectiveness and efficiency of an action, (Neely A., 1994)

As highlighted by Bacon (2008) performance measurement system is one of the most vital functions in the organization, measures enhance the decision-making process through proper reporting and interpretation.

Initial stages of performance measurement involve development and determination of performance measures as the performance measurement system is fabricated, it has to be implemented. It should be noted that the performance measurement system interacts with environment; the environment can be bifurcated into two different dimensions. The former is the internal environment that can be regarded as within an enterprise. Consecutively, the latter can be regarded as external environment that can be regarded as a market in which an enterprise competes (Neely, Gregory, \& Platts, 2005).

According to Peter (1996), the enterprise's internal environment involves the resources of an entity used to evaluate the strength and weakness of an enterprise, these resources might be related to human capital, processes, operations, structures , systems and financial aspects (Elnicki, 1971).

As discussed by Neely, Mike, \& Ken, (2005) performance measurement system has a strong connection with the environment. The environment has also been further classified in to two different dimensions the internal and external environment. The external environment is related to the market in which an organization competes while internal is the environment within the organization. (Neely, Gregory, \& Platts, 2005).

Therefore through extensive evaluation of the literature two main dimensions of performance measurement system can be regarded as internal and external environmental measures. Based on these two dimensions a performance measurement grid has been proposed in figure 1 . 
Figure 2 Dimensions for Performance Measurement

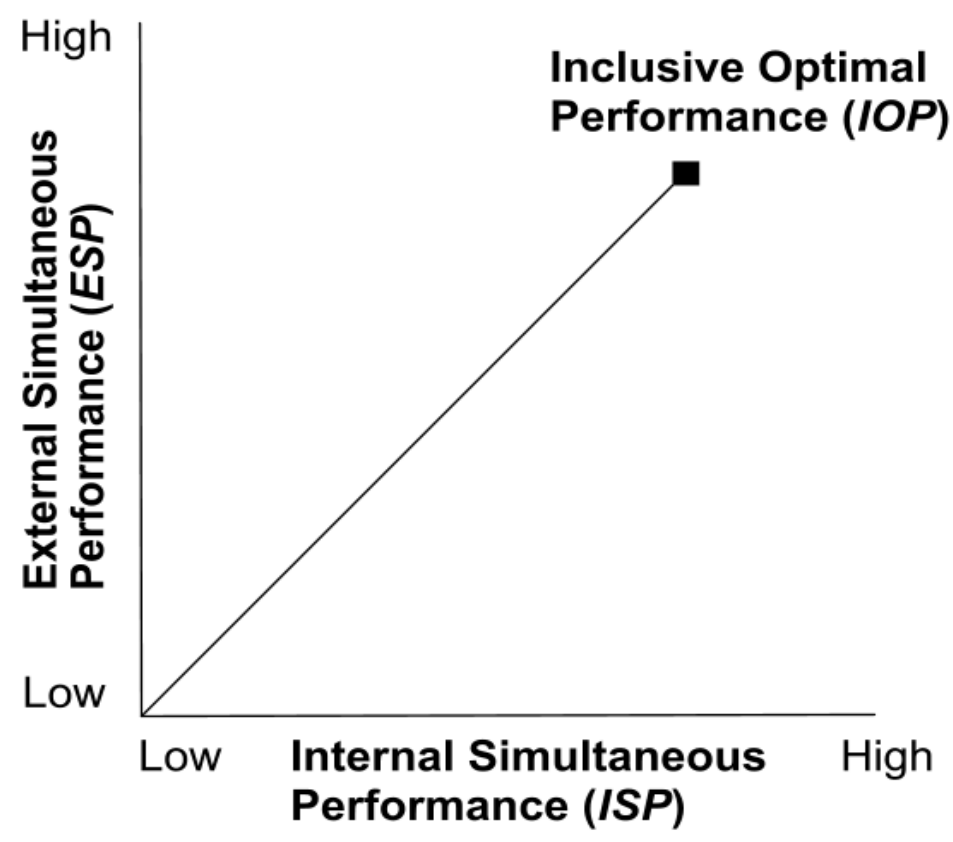

Figure 2 depicts the two dimensions for performance measurement. Following diagrammatic illustration can be applied to depict orientation of a particular industry, sector, and segment and can also be applied over an individual organization to evaluate its current orientation towards internal and external performance measurement. The diagram can also be used as a tool to balance internal and external performance measures to reach an optimal performance level. It's recommended that the higher the internal and external measures are applied the more optimal the performance measurement will be. In order to further clarify this issue Figure 3 and Figure 4 have been proposed in this paper.

While performing literature review and by observing of the current performance measurement systems in SMEs, it has been observed that most of the enterprises have failed to understand the dual nature of performance measurement systems, some are more oriented towards internal performance measurement, while others are concerned towards external factors, such a practice creates an imbalance amongst the internal and external dimensions for performance measurement (Keegan, Eiler, \& Jones, 1989; Garengo, Biazzo, \& Bititci, 2005).

One of the reasons for it is the improper bifurcation between internal and external performance. There is no framework to provide comprehensive understanding about what kind of measures are required to appropriately balance the input and output of an organization, primarily because the conceptual understanding of this bifurcation is not streamlined into particular conceptual domains, rather the orientation of it seems to be non-comprehensive. Because of this non particularity Page | 107 
companies tend to either incline towards internal performance in totality or towards external performance in totality. Even if they are able to maintain themselves in keeping both internal and external performance simultaneously, they are unable to capture appropriate outputs out of it (Keegan, Eiler, \& Jones, 1989; Pearce, 1983). In order to further analyze the performance measurement systems, we have adapted the psychology incepted concept of locus of control. According to the concept of locus of control a person has a certain degree of control over the outcomes of events in their life and the extent to which a person has influence over the outcome can be regarded as locus of control. The concept of locus of control can further be divided as internal locus of control and external locus of control. Internal locus of control can be defined as a belief that the person has a control over his life while on the other hand the concept of external locus of control is related with the belief that life is controlled by external factors outside the control of person such as fate, luck or chance etc (Rotter J. B., 1966).

This conceptualization is done because locus in context of an individual indicates the control one has in its own life, and the control one has on the matters that he cannot influence. Since an enterprise is considered as a separate entity, thus an organization or a company also needs to identify the factors of importance that needs to be controlled within and outside of the organization. Therefore, to understand this control mechanism we adopt the understanding of internal and external locus of control and conceptualize it as internal and external locus of performance. With the understanding of locus, the internal and external performance can be streamlined into appropriate control factors that can keep the company on track without having the question of which factor to work on, or which factor is of importance.

Figure 3 Locus of controls at organization level (hypothesis)

\section{Locus of Controls at Organizational Level}

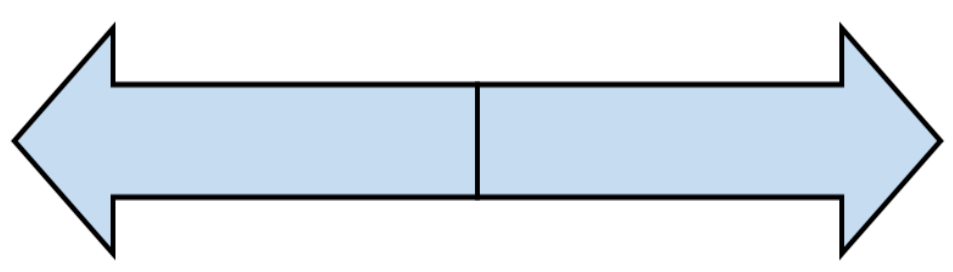

Internal factors that influence outcomes

- Financial Measures

- Human Capital

- Manufacturing controls
External factors that influence outcomes

- Market orientation

- Stakeholders relationships 
The figure 3 reflects the two different extremes having an impact over the organizations performance and thus affecting the outcomes. The internal and external factors illustrated in the figure 3 have been identified by a thorough literature review. According to the a model termed as SMART system designed at Wang laboratories that was proposed by (Cross \& Lynch, 1999) measures are divided as (externally focused) or (internally focused), The externally focused measures were more focused towards market orientations such as shares growth while internal ones were more related with the financial aspects. (Lynch \& Kelvin F. Cross, 1995; Gregory P. White, 1996). Additionally, Lukviarman (2008) has empathized upon the importance of managing and maintaining stakeholders relationship as an external performance measure (Lukviarman, 2008).

Moreover, an internal fit has been defined as the alignment between functional and competitive strategies (Venkatraman \& Camillus, 1984). Most of the operations management scholars have opposed external fit in comparison to the internal fit. A measure of production and manufacturing competence by Vickery's (1991) illustrates an example of assessing internal fit between business strategies and manufacturing strategies. Studies illustrate that performance is linked with the manufacturing control function having internal fit to the enterprise business strategy (Krause, 2002).

Further studies have also indicated human capital as an internal locus of control having an impact over organization's performance, Evans \& Davis (2005) have proposed a High Performance Work System (HPWS), according to the HPWS framework the internal social structure and human capital mediates the role between HPWS and performance of an enterprise. This research illustrates human capital as an essential aspect for a High-Performance Work System and for the effective enterprise performance. Thisresearch has aimed to furtherbreakdownthehumancapital practices and have closely evaluated the impact of human capital practices on the internal social structure and ultimately organizational performance (Evans \& Davis, 2005).

\section{5) DISCUSSIONON CONCEPTUALFINDING THROUGHTHEORETICAL UNDERSTANDING}

\section{1) INCLUSIVE OPTIMAL PERFORMANCE INTERDEPENDENCE WITH EXTERNAL AND INTERNAL SIMULTANEOUS PERFORMANCE}

Literature provides understanding of the relationship of inclusive optimal performance with external and internal simultaneous performance. Most enterprises have lacked in understanding the dual nature of performance measurement systems that jointly reflect inclusive optimal performance. Change in any one of the dual dimensions in actual practice can create creates an imbalance amongst the internal and external dimensions for performance measurement (Keegan, Eiler, \& Jones, 1989; Garengo, Biazzo, \& Bititci, 2005).

This simultaneous integration of performance to reflect optimal performance of organization is further clarified and discussed by Lynch and Cross (1999) through Page | 109 
a SMART model which are divided as (externally focused) or (internally focused) (Cross \& Lynch, 1999).

\section{2) EXTERNAL INCLUSIVE OPTIMAL PERFORMANCE INTERDEPENDENCE WITH MARKET ORIENTATION AND STAKEHOLDER RELATIONSHIPS}

As highlighted by Greenley (1995, Slater \& John (1994), external environmental influential relationship over orientation-performance (Gray, Matear, Boshoff, $\&$ Matheson, 1998). The externally focused measures are more focused towards market orientations such as shares growth while internal ones were more related with the financial aspects. (Lynch \& Kelvin F. Cross, 1995; Gregory P. White, 1996).

In a dynamic environment, companies needs to stay connected with key stakeholders, therefore uncertainty in the environment has become crucial for enterprises, in order to maintain the interest of stakeholders along with their own objectives (Barringer \& Harrison, 2000). As a matter of fact, management stakeholders relationship has been identified as a critical performance measure (Lukviarman, 2008).

\section{3) INTERNAL PERFORMANCE INTERDEPENDENCE WITH FINANCIAL ASPECT, MANUFACTURING CONTROL AND HUMAN CAPITAL}

Financial measures demonstrate the utilization of resources to evaluate the value addition. These characteristics make measures an important tool for constituted strategic planning, which act as a foundation for performance measurement in an organization (Galar, Parida, Kumar, Baglee, \& Morant, 2012). As discussed in literature by (Lynch and Cross, 1999) internal performance measures have a stronger relatedness with the financial aspects. (Lynch \& Kelvin F. Cross, 1995; Gregory P. White, 1996).

Moreover, an internal and inclusive fit has been identified and defined as the alignment between functional and competitive strategies (Venkatraman \& Camillus, 1984). Many of the operations management scholars have not favored external fit in comparison to the internal fit. A measure of production and manufacturing competence by Vickery's (A theory of production competence revisited, 1991) illustrates an example of assessing the relationship of internal fit between business strategies and manufacturing strategies. Through studies it can be understood that performance has strong link with the manufacturing control function that has internal fit to the enterprise business strategy (Krause, 2002).

There is also an indication in studies that human capital as a parameter for the internal simultaneous performance that has an impact over organization's inclusive optimal performance. Evans \& Davis (2005) proposed a High Performance Work System (HPWS), according to which the internal social structure and human capital mediates the role between HPWS and performance of an enterprise. Therefore, in this research it is conceptualized that human capital is an essential aspect for a 
High-Performance Work System and for the effective enterprise performance. This break down of the human capital practices can be closely evaluated through the impact of human capital practices on the internal social structure and ultimately organizational performance, that is inclusive optimal performance (Evans \& Davis, 2005).

Figure 4 Grid reflecting theoretical positioning of companies towards internal and external simultaneous performance measures

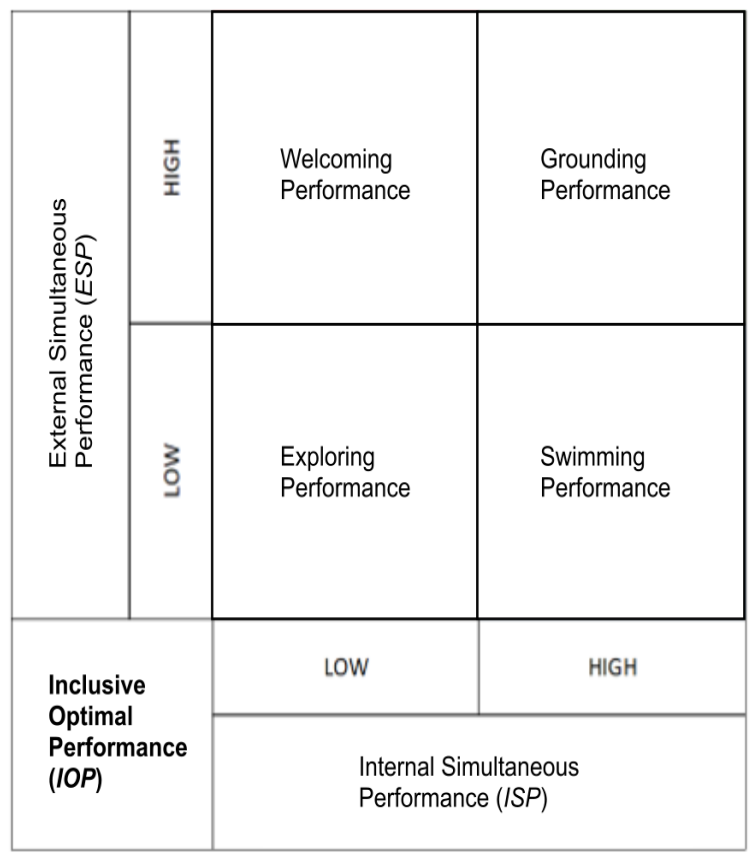

The Figure 4 further divides and reflects the different categories that can be allotted to the organizations. These categories are self-generated and are based upon the level of concentration of internal and external performance measures applied by organizations. This grid can be used to categorize organizations according to their behaviors towards external and internal performance measurement. The grid can act as a useful tool to illustrate and to analyze different kind of organizations based on locality, size or industry and one can study the type of concentration or type of orientations being followed and thus after the study of specific group gaps between internal and external performance measures can be identified and worked upon in order to achieve optimal performance.

According to the suggested grid, organizations lie in any of these four orientations: explorers, welcomes swimmers and grounders. As discussed above, these terms are self-generated and can be used to reflect the overall orientation of organization towards internal and external factors. The "Welcoming performers" can be defined as the companies that are open towards environment and accept change, these organizations have more concentration towards measuring external performance. 
In contrast however there are some organizations that do not focus on external environment and do not accept change, these organizations have restricted view and are more focused on contemporary and conventional measures; such companies can be regarded as "Swimming performers".

Moreover, there are certain organizations that focus over internal and external environment both, these enterprises strive to balance between internal and external performance measures and thus, they incorporate a wide variety of internal and external measures. Such organizations can be regarded as "Grounding Performers". On a contrary there are certain organizations that are dimensionless and are unfocused in terms of both internal and external factors can be regarded as "Exploring Performers". Explorers have a lack of application of both internal and external measures.

It is to be noted that if an organization currently lies in one orientation it can shift in the other orientation depending on the adoption of measures. There are many examples of organizations that could be classified as explorers as they did not have proper measures but gradually, they adopted appropriate performance measures and shifted towards performer's category. These tools will help in identifying an organization's orientation towards performance measurement. We believe that once the organizations orientation has been identified, it would be much easier to improve the organizations performance measures towards optimality and balanced approach.

\section{6) RESULTS}

Figure 5 Full theoretical framework for Inclusive Optimal Performance (IOP)

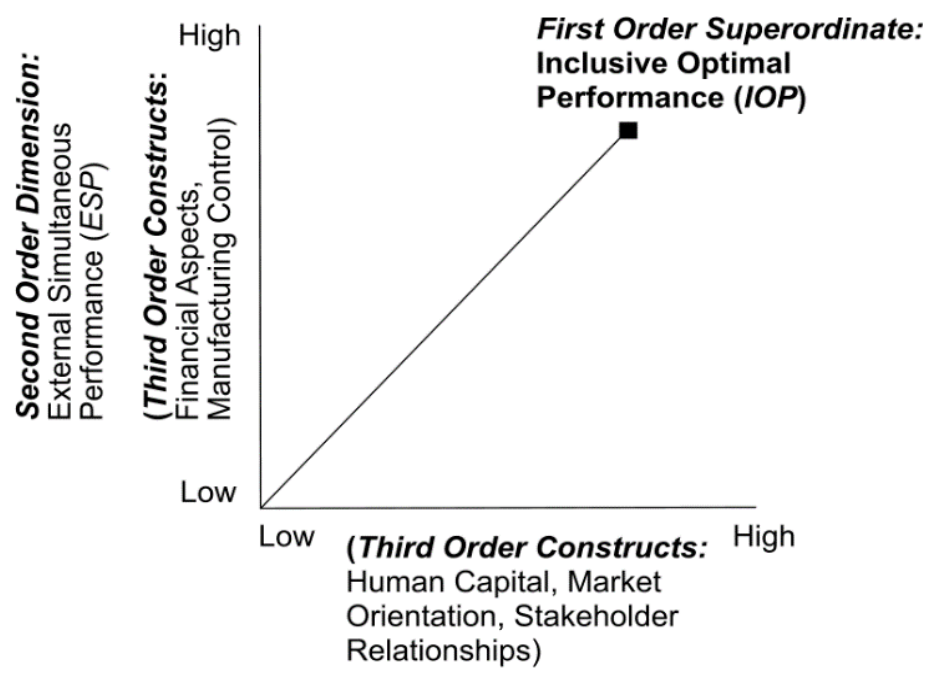

Second Order Dimension:

Internal Simultaneous

Performance (ISP) 
IBT JOURNAL OF BUSINESS STUDIES (IBT-JBS) Volume 16 Issue 1, 2020

In order to design and propose a formal sturcture for optimal performance measurement, Theoratical grounding has been amalagated and merged in a manner to depict an illustrative model in Figure 5, this is the proposed model encompassing required variables and their relationships required for an optimum performance measurement system.

\section{1) FINANCIAL MEASURES}

The financial measures are mostly exploited by the top management of an enterprise. Financial measures illustrate the utilization of resources by an enterprise in order to evaluate the value addition. These characteristics make these measures an important tool for strategic planning and constitute these measures as a foundation for performance measurement in an organization(Galar, et al., 2012).

A report named "KPI Examples Review" has studied the different types of financial measures and has also categorized these measures in six categories: profit measures, cash flow, profitability, liquidity, and solvency and capital market ratios(Review, 2016).

\section{2) MANUFACTURING CONTROLS}

A study by Skinner(1969) has linked strategy and performance evaluation. According to Skinner "the connection between manufacturing and corporate success is rarely seen as more than the achievement of high efficiency and low costs". He further emphasized that manufacturing controls are targeted towards resource utilization, quality, flows, inventory, and time, and the outcome can be evaluated in terms of productivity, service, quality flexibility and innovation. (Skinner, 1969).

Even though every author has a set of priorities, the result of survey instrument by Vickery \& Markland(1993) displayed that there were 31 items but manufacturing control cannot be held liable for all items, The identified items have also been considered have also been discussed by Maskell, 1991) in his research "Performance Measurement for World Class Manufacturing".

Items identified by (Vickery \& Markland, 1993) and (Maskell, 1991)for which manufacturing control is responsible are:

- Quality (conformance to specifications, reliability and durability);

- Cost;

- Flexibility and Innovation (volume and process);

- Delivery dependability; and

- $\quad$ Speed (delivery speed and lead time).(Vickery \& Markland, 1993), (Maskell, 1991)

\section{3) HUMAN CAPITAL}

The study by Ostroff \& Cheri (1992) evaluates the relationship between job satisfaction, attitudes and performances. Significant and important relationships 
were discovered between job satisfaction, attitudes and performance measurement, The research conculded that it is important for an organization to anlyze the factors that are important to satisfy employees, increment in the satisfaction level of employees would lead towards effeciency and effectiveness of an organization (Ostroff \& Cheri, 1992).

It has also been emphasized in previous literature that the role of intellectual capital cannot be denied upon performance measurement. It is becoming increasingly important for researchers in field of intellectual capital to justify the impact over performance. Bernard, et al (2003)has analyzed the reasons why enterprises measure the intellectual capital and existing evidences relevant to justify the measurement of intellectual capital as a significant factor(Bernard, et al., 2003).

The studies and researches relating to quantify and report intellectual capital have increased rapidly, e.g. (Can ibano, et al., 2000; Guthrie, 2001). The researches related to intellectual capital initiated from 1990's were related to enhance the awareness regarding the value of intangible resources in an organization, classification models for intellectual capital were also developed (Hall, 1989; Itami \& Thomas , 1991; Roos, et al., 1997; Brooking, 1996) .Specified importance over the quantification of intellectual capital related to formation of frameworks and guidelines to support the foundation concepts were being practiced (Sveiby, 1997; Bontis, et al., 1999; Mouritsen, et al., 2000; Lev, 2001). However the research and studies in the subject of intellectual capital measurement frameworks is still inclined towards growth, researchers are working towards development of enhanced measures and indicators and in addition to that studies are being done in in order to further improve reporting, disclosures and performance measurement systems (Bernard, et al., 2003).

\section{4) MARKET ORIENTATION}

Customer perspectives involves external perception and view of customers of an enterprise, and is a vital element of performance measurement (Salaman, et al., 2013). Due to the impact of external market environment especially in highly competitive era, markets require companies to be responsive to customer needs(Brendan, et al., 1998). Two groups of American researchers analyzed the relation between performance and market orientation (Kohli \& Jaworski, 1990; Narver \& Stanley, 1990; Jaworski \& Ajay, 1993).

It is also highlighted by Greenley (1995) from United Kingdom and Slater \& John(1994)from America that environmental influences have an impact over orientation-performance relationship(Brendan, et al., 1998). Market orientation focuses upon such culture and values that emphasizes over value addition for customers is essential for earnings(Gebhardt, et al., 2006). Market performance measurement acts as an instrument setting measures towards goals and objectives (Morgan, et al., 2002). These goals can be related towards different dimensions of market-oriented performance such as customers (e.g. Distribution of sales production and customer wise), competitors (e.g., relative market share gains). Therefore, marketing orientation and market performance measurement act to further improve the enterprise performance measurements through value additions 
in the markets (Verhoef \& Peter, 2009).

\section{5) STAKEHOLDERS RELATIONSHIPS}

Additionally, in order to be competitive in such a dynamic environment, it is required for companies to remain connected with key stakeholders. Thus, in order to respond to the uncertainty in the environment it has become more crucial for enterprises to maintain the interest of stakeholders along with their own objectives (Barringer \& Harrison, 2000). The stakeholder as a term is a combination of variety of concepts, therefore literature methodologies and context as well as researches that are used to understand customers and suppliers can be inclusive of stakeholders as well(Lukviarman, 2008).

While applying Stakeholder approach in strategic processes questions have been raised in relation to performance measurement. These questions are;

- What are stakeholder interests and / or rights?

- What responsibility has the firm to each stakeholder's group? How do we measure how well an organization is doing with its stakeholders?

- What are the relevant variables?

- What are appropriate measures?

- What are appropriate measures of the relative power of suppliers, customers, and other stakeholders? (Freeman, 1983; Vinten, 2001, p. 41)

Measuring performance in terms of suppliers and customers is an important aspect as discussed by Freeman (1983) andVinten (2001), strategic performance measurement system have an impact through alignment of organizational development and learning. In Accordance with Meyer and Gupta (1994) amongst variety of forces that involves applicability of performance measurement, positive and pre-serve learning also exists(Chenhall, 2005).

Studies have also highlighted that Jobs satisfaction as a significant measure and is linked towards employee retention, According to the researches employees that are highly satisfied are more efficient and possess high level of dedication towards their role (Harper, et al., 2015). 
Figure 6 Derived Conceptual Framework based on Theoretical Framework for Inclusive Optimal Performance (IOP)

$\begin{array}{cccc}\text { First Order } & \text { Second Order } & \text { Third Order } & \text { Measures } \\ \text { Superordinate } & \text { Dimensions } & \text { Constructs } & \text { S }\end{array}$

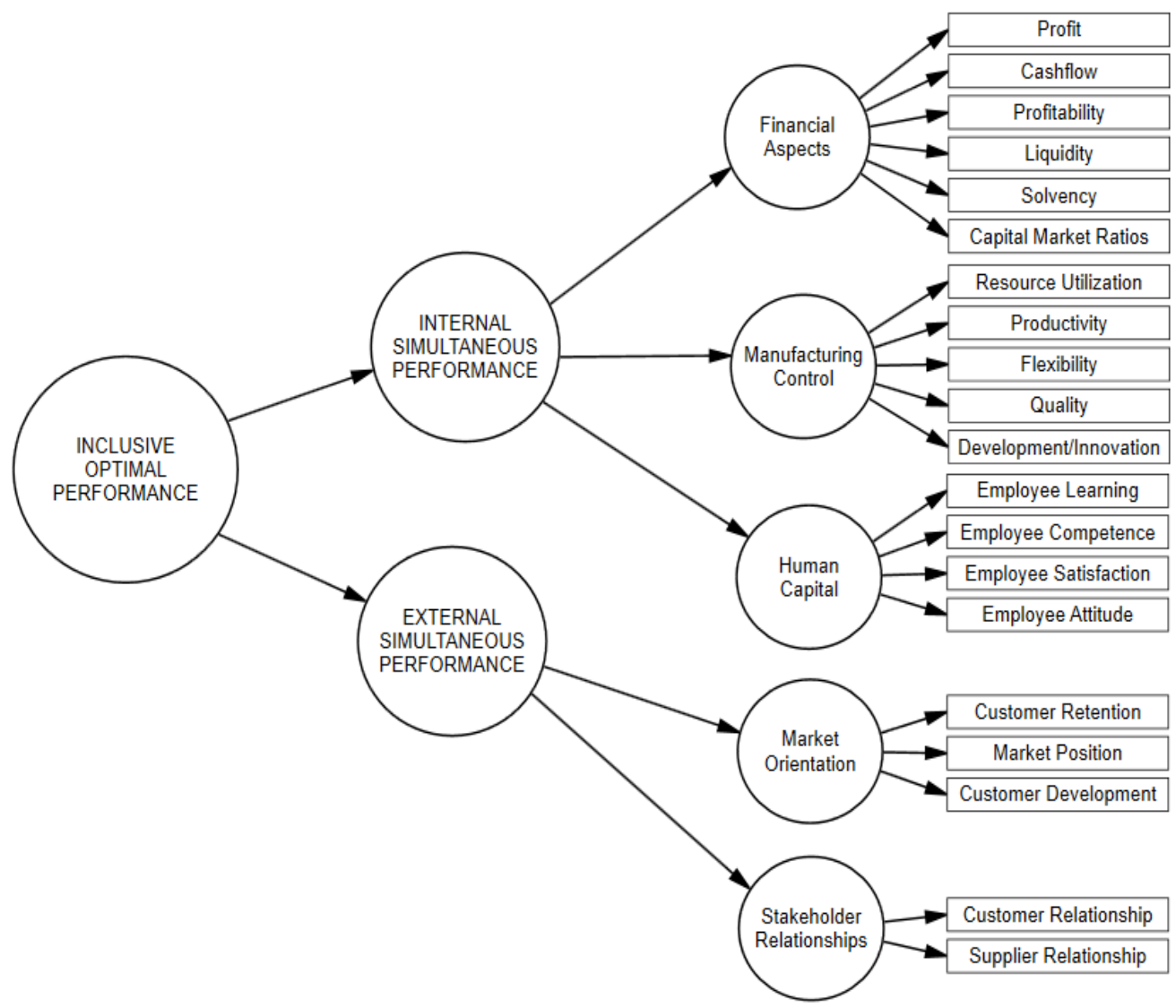

\section{7) CONCLUSION:}

As the Small Medium Enterprises (SME's) and their inclination towards the conviction that their products are inherently inferior to that of the larger enterprises is one observed persistently, however they outnumber the larger enterprises in count. But the performance measures that big enterprises usually tend to invest on are that considered as a cost overlooked by SME's. Although there has been some research done in the performance measurement methodologies there wasn't much on the applicative practicality. In addition there has been significant focus on the research for large companies even for the evaluation of the CF's but to date there has not been much focus on that of the SME's (Yew Wong, 2005).

Hence the performance measurement system in this literature after thorough 
evaluation sought towards a system that not only measures the results but also measures the drivers of the results. The study can further be used to identify the neglected areas and pain points of performance measurement systems applied by SME. Additionally, this framework for performance measurement that can be applied by SMEs to balance their internal and external performance measurement. Undoubtedly the suggested framework will not only enhance the current performance measurement systems but will ensure a balanced application of internal and external measures.

The propositions however were limited with the inherent lack of previous literature on the concurrent foundations of this study and certain aspects that that still have ample space for further research and evaluation. Albeit, this research can put on a weight towards the factors for optimal success given the fact that the gap of the measurement of performance that needs to be filled with the in the SMEs can be efficiently sought through the applicability of the proposed framework. Though, the occurrence of the limitation of the lack of in-depth analysis in the previous literature on the applicative practicality of this approach is one that is not inherently improbable. The SME's can achieve an optimum level for favorable performance outcomes if greater focuses were to be placed on the balance between external and internal factors of performance as centered by this research.

The inclusive optimum performance theory with implied the constructs of the aspects of organizational performance through mutual relationship between internal and external performance factors. This simultaneous nature of working between the performance factors has laid the foundation of inclusive approach to achieving internal and external organization success, that can help make organizations come out of the one-sided competitiveness. After the exhaustive review of the various external factors such as the market drivers, stockholders and the internal as that of the human capital and finding the inherent balance between them, it was suffice to state that the measurement of these drivers can be an investment worth spending for the small enterprises to obtain optimal success factors and ensures the inherent increment towards favorable outcomes for the SMEs.

\section{REFERENCES}

Abbasian-Naghneh, S., Samiei, M., Felahat, M., \& Mahdavi, M. (2014). A New Integrative Approach Based on Balanced Scorecard, Data Envelopment Analysis, and Management Performance to Prioritize Research and Development Projects. In In Handbook of Research on Strategic Performance Management and Measurement Using Data Envelopment Analysis (pp. 324348). IGI Global.

Bacon, C. R. (2008). Practical portfolio performance measurement and attribution. John Wiley \& Sons.

Barringer, B. R., \& Harrison, J. S. (2000). Walking a Tightrope: Creating Value Through Interorganizational Relationships. Jounal of Management, 26(3), 367403. 
Bontis, N., Dragonetti, N. C., Jacobsen, K., \& Roos, G. (1999). The knowledge toolbox:: A review of the tools available to measure and manage intangible resources. European management journal, 17(4), 391-402.

Brooking, A. (1996). Intellectual capital: Core Asset for the Third Millennium Enterprise,. Management Journal, 17(4).

Can ibano, L., Garci'a-Ayuso, C.M., \& Sa'nchez, P. (2000). The value relevance and managerial implications of intangibles: A literature review. . Classification of intangibles, , 712, 79-126.

Carter, J., \& Goldstein, D. (2014). Sympathoneural and Adrenomedullary Responses to Mental Stress. Comprehensive Physiology.

Cavaco, N. M., \& Machado, V. C. (2014). Sustainable competitiveness based on resilience and innovation - an alternative approach. International Journal of Management Science and Engineering Management.

Chenhall, R. H. (2003). Management control systems design within its organizational context: findings from contingency-based research and directions for the future. Accounting, organizations and society, 28(2), 127-168.

Chenhall, R. H. (2005). Integrative strategic performance measurement systems, strategic alignment of manufacturing, learning and strategic outcomes: an exploratory study. Accounting, organizations and society, 30(5), 395-422.

Chennell, A., Dransfield, S., Field, J., Fisher, N., Saunders, I., \& Shaw, D. (2000). OPM: a system for organisational performance measurement. . In Proceedings of the performance measurement-past, present and future conference, Cambridge , (pp. 19-21).

Cross, K. F., \& Lynch, R. L. (1999). Measure Up!: Yardsticks for Continuous Improvement. Blackwell publishing.

Darell, S. (2016). The KPI Examples Review. Retrieved from List of Top 20 Financial KPI: Examples of the Most Popular Key Performance Indicators Defined by Categories: http://kpi-examples.blogspot.com/2016/01/list-oftop-20-financial-kpi-examples-of-key-performance-indicators-defined-bycategories.html

Diamond, P. (1996). Testing the internal consistency of contingent valuation surveys. Journal of Environmental Economics and Management, 30(3), 337347.

Dostilio, L., Brackmann, S., Edwards, K., Harrison, B., Kliewer, B., \& Clayton, P. (2012). Reciprocity: Saying what we mean and meaning what we say. Michigan Journal of Community Service Learning. 
IBT JOURNAL OF BUSINESS STUDIES (IBT-JBS) Volume 16 Issue 1, 2020

Dutton, J. M., \& Freedman, R. D. (1985). External environ- ment and internal strategies: calculating, experimenting and imitating in organizations. In R. Lamb \& P. Shrivastava (Eds.). Advances in strategic management, 3.

Elenkov, D. S. (1997). Strategic uncertainty and environmental scanning: The case for institutional influences on scanning behavior. . Strategic management journal, 18(4), 287-302.

Elnicki, R. (1971). The genesis of management accounting. Management Accounitng, Vol. 52, 52(10), 15-17.

Evans, W. R., \& Davis, W. D. (2005). High-Performance Work Systems and Organizational Performance: The Mediating Role of Internal Social Structure. Journal of Management, 31(5), 758-775.

Fernández, R. S., \& Bonillo, M. I. (2006). Consumer perception of value: Literature review and a new conceptual framework. Journal of Consumer Satisfaction, Dissatisfaction and Complaining Behavior.

Ferreira, A., \& Otley, D. (2009, December). The design and use of performance management systems: An extended framework for analysis. Management Accounting Research, 20(4), 263-282. doi:https://doi.org/10.1016/j. mar.2009.07.003

Freeman, E. R. (1983). Strategic management: A stakeholder approach. Advances in strategic management, 1(1), 31-60.

Galar, D., Parida, A., Kumar, U., Baglee, D., \& Morant, A. (2012). The measurement of maintenance function efficiency through financial KPIs. Journal of Physics: Conference Series, 364(1).

Garengo, P., Biazzo, S., \& Bititci, U. S. (2005). Performance measurement systems in SMEs: A review for a research agenda. International Journal of management Reviews, 7(1), 25-47.

Gebhardt, G. F., Carpenter, G. S., \& Sherry Jr, J. F. (2006). Creating a market orientation: A longitudinal, multifirm, grounded analysis of cultural transformation. Journal of marketing volume , 70(4), 37-55.

Gray, B., Matear, S., Boshoff, C., \& Matheson, P. (1998). Developing a better measure. European Journal of Marketing, 32(9), 884-903.

Greenley, G. E. (1995). Market orientation and company performance: empirical evidence from UK companies. British journal of management, 6(1), 1-13.

Greenley, G., \& Foxall, G. (1997). Multiple stakeholder orientation in UK companies and the implications for company performance. Journal of Management Studies, 34(2), 259-284.

Page | 119 
IBT JOURNAL OF BUSINESS STUDIES (IBT-JBS) Volume 16 Issue 1, 2020

Gregory P. White. (1996). A survey and taxonomy of strategy-related performance measures for manufacturing. International Journal of Operations \& Production Management, 16(3), 42 - 61.

Gulbro, R. S. (2000). Are small manufacturers failing the quality test? Industrial Management \& Data Systems, 100(3), 76-80.

Guthrie, J. (2001). The management, measurement and reporting of intellectual capital. Journal of Intellectual Capital, 2(1), 27-41.

Hall, R. (1989). The management of intellectual assets: a new corporate perspective. Journal of general management, 15(1), 53-68.

Hambrick, D. C. (1982). Environmental scanning and organizational strategy. Strategic Management Journal, 3, 159-174.

Hansen, O. E., Sonderga ${ }^{\circ}$ d, B., \& Meredith, S. (2002). Environmental innovations in small and medium sized enterprises. Technology Analysis \& Strategic Management, 14, 37-56.

Harper, E., Castrucci, B. C., Bharthapudi, K., \& Sellers. (2015). Job Satisfaction: A Critical, Understudied Facet of Workforce Development in Public Health. Journal of Public Health Management and Practice, 21.

Houwer, J. D. (2020). Revisiting classical conditioning as a model for anxiety disorders: A conceptual analysis and brief review. Behaviour Research and Therapy.

Hudson, M., Bennett, J.P., Smart,A.,\& Bourne, M.(1999).Performancemeasurement for planning and control in SMEs. Global Production Management, IFIP TC5/ WG5.7 International Conference on Advances in Production Management Systems, , (pp. 219-225). Berlin.

Itami, H., \& Roehl, T. W. (1991). Mobilizing invisible assets. Harvard University Press.

Jaworski, B. J., \& Ajay, K. K. (1993). Market orientation: antecedents and consequences. Journal of marketing, 57(3), 53-70.

Jelinek, M. (1979). Institutionalizing innovation, a study of organizational learning systems. Greenwood.

Keegan, D., Eiler, R., \& Jones, C. (1989). Are your performance measures obsolete? Management, 70, 45-50.

Kennerley, M., \& Neely, A. (2000). A framework of the factors affecting the evolution of performance measurement systems. International Journal of Operations \& Production Management, 22(11), 1222-1245. 
IBT JOURNAL OF BUSINESS STUDIES (IBT-JBS) Volume 16 Issue 1, 2020

Kohli, A. K., \& Jaworski, B. J. (1990). Market orientation: the construct, research propositions, and managerial implications. Journal of marketing, 54(2), 1-18.

Krause, M. P. (2002). Strategic consensus in the internal supply chain: Exploring the manufacturing-purchasing link. International Journal of Production Research, 40(13), 3075-3092.

Kueng, P. (2000). Process performance measurement system: a tool to support process-based organisations. Total Quality Management, 11(1), 67-85.

Kureshi, N. I., Mann, R., Khan, M. R., \& Qureshi, M. F. (2009). Quality Management Practices of SME in Developing Countries. Journal of Quality and Technology Management, 5(2), 63-89.

Laitinen, E. K. (2002). A dynamic performance measurement system: evidence from small Finnish technology companies. Scandinavian journal of management, 18(1), 65-69.

Lev, B. (2001). Intangibles: Management, Measurement, and Reporting. Washington DC, USA: Brookings Institution Press.

Lukviarman, N. (2008). Performance measurement: A stakeholder approach. Sinergi: Kajian Bisnis dan Manajemen, 10(2).

Lynch, R. L., \& Kelvin F. Cross. (1995). Measure Up!: Yardsticks for Continuous Improvement. Cambridge: Wiley.

Marr, B., Gray, D., \& Neely, A. (2003). Why do firms measure their intellectual capital. Journal of Intellectual Capital, 4(4), 441-464.

Maskell, B. (1991). Performance Measurement for World Class Manufacturing: A Model for American Companies. CRC press.

Meyer, J., Becker, T., \& Vandenberghe, C. (2004). Employee Commitment and Motivation: A Conceptual Analysis and Integrative Model. Journal of Applied Psychology.

Meyer, M., \& Gupta, V. (1994). 'The Performance Paradox. Research in Organizational Behavior, 16, 309-369.

Morgan, N.A., Clark, B. H., \& Goonera, R. (2002). Marketing productivity, marketing audits, and systems for marketing performance assessment: integrating multiple perspectives. . Journal of business research, 55(5), 363-375.

Morris , M., \& Sexton , D. (1996). The Concept of Entrepreneurial Intensity: Implications for Company Performance. Journal of Business Research, 5-13. 
Mouritsen, J., Bukh, P. N., Larsen, H. T., Hansen, G., Stakemann, B., Jeppesen, G., \& Nielsen, L. H. (2000). A guideline for intellectual capital statements-a key to knowledge management. Ministry of Trade and Industry, Danish Agency for Trade and Industry.

Murschetz, P. (2005). Interactivity and leadership effectiveness: A concept review and analysis of email as an interactive leadership tool. Leadership in the media industry-Changing contexts, emerging challenges.

Narver, J. C., \& Stanley, S. F. (1990). The effect of a market orientation on business profitability. Journal of marketing, 54(4), 20-35.

Neely, A. (1994). Performance measurement system design-third phase. In Performance Measurement System Design Workbook 1.

Neely, A. D., \& Mills, J. F. (1993). Manufacturing in the UK - report on a survey of performance measurement and strategy issues in UK manufacturing companies. London: Manufacturing Engineering Group.

Neely, A., Gregory, M., \& Platts, K. (2005). Performance measurement system design: A literature review and research agenda. . International Journal of Operations \& Production Management, 25(12), 1228-1263.

Negro, R. W. (2015). Dry powder inhalers and the right things to remember: a concept review. Dal Negro Multidisciplinary Respiratory Medicine.

Ostroff, C. (1992). The relationship between satisfaction, attitudes, and performance: An organizational level analysis. Journal of applied psychology, 77(6), 963.

Pearce, J. A. (1983). The relationship of internal versus external orientations to financial measures of strategic performance. Srraregic Management Journal, 4, 297-306.

Roos, J., Edvinsson, L., \& Dragonetti, N. C. (1997). Intellectual capital: Navigating the new business landscape. Springer.

Rotter, J. B. (1954). Social learning and clinical psychology. Johnson Reprint Corporation.

Rotter, J. B. (1966). Generalized expectancies for internal versus external control of reinforcement. Psychological Monographs: General and Applied, 80, 1-28.

Shek, D., Yu, L., \& Busiol , D. (2015). Preventing and Combating Internet Addiction: A Concept Review. Student Well-Being in Chinese Adolescents in Hong Kong.

Shi, Q., Li, F., Hu, Q., \& Wang, Z. (2018). Dynamic demand control for system frequency regulation: Concept review, algorithm comparison, and future vision. Electric Power Systems Research. 
Shrivastava, A., Boylan, J., Bureau, Y., De Sousa, A., \& Shah, N. (2015). Biological Trajectory for Psychosocial Risk Factors in Psychiatric Disorders-A Concept Based Review. Open Journal of Psychiatry.

Simons, R. (1994). Levers of control: How managers use innovative control systems to drive strategic renewal. Harvard Business Press.

Skinner, W. (1969). Manufacturing - missing link in corporate strategy. Harvard Business Review, 47(3), 136-145.

Slater, S. F., \& Narver, J. C. (1994). Does competitive environment moderate the market orientation-performance relationship? Journal of marketing, 58(1), 4655 .

SMEDA. (2017). SME Policy development. Retrieved from http://www.smeda. org/index.php?option $=$ com_content\&view $=$ article \&id=58:smepolicydevelopment\&catid=2\&Itemid=101

Spillane, J., Halverson, R., \& Diamond, J. (2004). Towards a theory of leadership practice: a distributed perspective. Journal of Curriculum Studies.

Sveiby, K. E. (1997). The new organizational wealth: Managing \& measuring knowledge-based assets. Berrett-Koehler Publishers.

Tamayo, J., Romero, J., Gamero, J., \& Román, J. M. (2015). Do Innovation and Cooperation Influence SMEs' Competitiveness? Evidence From the Andalusian Metal-Mechanic Sector. Innovar, http://dx.doi.org/10.15446/ innovar.v25n55.47226.

Venkatraman, N., \& Camillus, J. (1984). Exploring the concept of fit in strategic management. Academy of Management Review, 9, 513-525.

Verhoef, P. c., \& Peter, S. L. (2009). Understanding the marketing department's influence within the firm. Journal of marketing, 73(2), 14-37.

Vickery, S. D., \& Markland. (1993). Production competence and business. Decision Sciences Vol 24, 435-55.

Vickery, S. K. (1991). A theory of production competence revisited. Decision sciences, 22(3), 635-643.

Vinten, G. (2001). Shareholder versus stakeholder-is there a governance dilemma? Corporate Governance: An International Review, 9(1), 36-47.

Wang, G. J., Volkow, N., Thanos, P., \& Fowler, J. (2004). Similarity between obesity and drug addiction as assessed by neurofunctional imaging: a concept review. Journal of addictive diseases.

Page $\mid 123$ 
IBT JOURNAL OF BUSINESS STUDIES (IBT-JBS) Volume 16 Issue 1, 2020

Yew Wong, K. (2005). Critical success factors for implementing knowledge management in small and medium enterprises. Industrial management \& Data systems, 105(3), 261-279. 